\title{
Correlations of Structural, Dielectric, Magnetic and Magnetoelectric Properties of $\mathrm{Ca}_{1-\mathrm{x}} \mathrm{Sr}_{\mathrm{x}}\left(\mathrm{Fe}_{0.5} \mathrm{Ta}_{0.5}\right) \mathrm{O}_{3}$ Multiferroic Ceramics
}

\author{
M. K. H. Bhuiyan ${ }^{1}$, M. A. Gafur ${ }^{2}$, M. N. I. Khan ${ }^{3}$, A. A. Momin'1, A. K. M. Akther Hossain ${ }^{1}$ \\ ${ }^{1}$ Department of Physics, Bangladesh University of Engineering \& Technology, Dhaka, Bangladesh \\ ${ }^{2}$ Pilot Plant \& Process Development Centre, Dhaka, Bangladesh \\ ${ }^{3}$ Materials Science Division, Atomic Energy Centre, Dhaka, Bangladesh \\ Email: *kamrul04122@gmail.com
}

How to cite this paper: Bhuiyan, M.K.H. Gafur, M.A., Khan, M.N.I., Momin, A.A. and Akther Hossain, A.K.M. (2017) Correlations of Structural, Dielectric, Magnetic and Magnetoelectric Properties of $\mathrm{Ca}_{1-\mathrm{x}} \mathrm{Sr}_{\mathrm{x}}\left(\mathrm{Fe}_{0.5} \mathrm{Ta}_{0.5}\right) \mathrm{O}_{3}$ Multiferroic Ceramics. Materials Sciences and Applications, 8, 64-84.

http://dx.doi.org/10.4236/msa.2017.81005

Received: November 22, 2016

Accepted: January 8, 2017

Published: January 11, 2017

Copyright () 2017 by authors and Scientific Research Publishing Inc. This work is licensed under the Creative Commons Attribution International License (CC BY 4.0).

http://creativecommons.org/licenses/by/4.0/

\begin{abstract}
Conventional solid state reaction technique was used to synthesize $\mathrm{Ca}_{1-\mathrm{x}} \mathrm{Sr}_{\mathrm{x}}\left(\mathrm{Fe}_{0.5} \mathrm{Ta}_{0.5}\right) \mathrm{O}_{3}$ multiferroic ceramics (where $x=0.0,0.1,0.2,0.3,0.4$ and 0.5). Powder of ingredients was mixed thoroughly in stoichiometric amount and calcined at $1150^{\circ} \mathrm{C}$ for $5 \mathrm{~h}$. Disk and toroid shaped samples prepared from each composition were sintered at $1450^{\circ} \mathrm{C}$ for $5 \mathrm{~h}$. The XRD analysis confirms that all compositions are single phase cubic perovskite structure. The theoretical and bulk density increases with increase of Sr content, which may be attributed to the fact that the atomic weight and density of Sr are larger than those of $\mathrm{Ca}$. The average grain size increased with increasing $\mathrm{Sr}$ content up to $x=0.2$, and then decreased with further increase of Sr content. Frequency dependent dielectric constant shows usual dielectric dispersion at lower frequencies due to Maxwell-Wagner type interfacial polarization. The higher values of real and imaginary part of impedance at lower frequencies are also due to the fact that all kinds of polarization mechanism are present and increase with Sr content indicating the enhancement property of the composition. The continuous dispersion on increasing frequency contributes to the conduction phenomena. Two semicircles correspond to the grain boundary and grain resistance separately. The complex modulus analysis reveals the polaron hopping and negligibly small contribution of electrode effect. The continuous dispersion on increasing frequency may be contributed to the conduction phenomena. The ac conductivity, $\sigma_{a c}$ was derived from the dielectric measurement and it increases with increase of frequency for all the compositions and can also be explained on the basis of polaron hopping mechanism. At higher frequencies conductive grains are more active, and thereby increases of hopping of charge carrier contribute to rise in conductivity. The real part of initial permeability increased with increasing Sr content up to $x=0.2$, and
\end{abstract}


then decreased further increasing the $\mathrm{Sr}$ content. Firstly, it increased due to the higher values of grain size, and then decreased with the $\mathrm{Sr}$ content due to the lowering the grain size. The saturation magnetization, $M_{s}$, increases for $x$ $=0.2$ and then decreases with increasing $\mathrm{Sr}$ content due to the pore acted as a pinning centre of electron spin; thereby Ms decreases also due to the grain size which is well supported by the permeability results. The decrease of magnetoelectric voltage coefficient $\alpha_{M E}$ with content may be attributed to the increased porosity in the sample. The presence of the pores breaks the magnetic contacts between the grains. The highest value of $\alpha_{M E}$ is $42.22 \mathrm{mV} \cdot \mathrm{cm}^{-1} \cdot \mathrm{Oe}^{-1}$ for the composition $x=0.2$ which is attributed to the enhanced mechanical coupling. It was revealed that there is a dramatic influence of Sr with content $x=0.2$ and also has strong correlations on grain size as well as magnetic and magnetoelectric properties.

\section{Keywords}

Perovskite, Impedance Spectroscopy, Initial Permeability, Saturation Magnetization, Magnetoelectric Voltage Coefficient

\section{Introduction}

Ceramics having multiferroic properties are very appealing materials from a functional point of view, because they can show a wide range of properties: ferroelectricity, ferromagnetism, ferroelasticity and can also be metals, insulators, semiconductors, superconductors, etc. Furthermore, the coupling between some of these properties can give rise to new applications [1]. Particular interest has been aroused by the possibility of new magnetoelectric coupling mechanisms [2] [3], which was introduced in 1926 by Debye. Later on, Dzyaloshinskii predicted that this type of coupling, which was observed afterward by Astrov [4], had the potential for exploitation in technological applications [5] [6] [7]. Although a certain number of materials with ferroelectricity and ferromagnetism exist, the coupling between those two properties is not always large enough [8]. Recently, Xin Lv. et al. have studied dielectric and magnetic properties of $\operatorname{Sr}\left(\mathrm{Fe}_{1 / 2} \mathrm{Ta}_{1 / 2}\right) \mathrm{O}_{3}$ and the nonlinear magnetic behavior was observed at 10 and $50 \mathrm{~K}$ [9]. The transition temperature of $\mathrm{SrFeO}_{3}$ and $\mathrm{CaFeO}_{3}$ was also reported to vary with their ionic radii by several authors [10] [11] [12]. This compound having general formula $\mathrm{ABO}_{3}$ shows the perovskite structure. It is well known that the dielectric properties strongly depend on processing conditions during sample preparation as well as on small amounts of doping. Concerning impurity effects, results reported in literature lead to a systematic and significant decrease of the effective dielectric constant [13] [14], which is accompanied by a concomitant strong decrease in conductivity [15] [16]. Especially, samples doped with marginal amounts of $\mathrm{Sr}$ with the nominal chemical composition revealed strong doping effects, dielectric, both in the magnetic and magneto electric response. The detected decrease of conductivity by several orders of magnitude directly influ- 
ences the Maxwell-Wagner like relaxation and shifts the relaxation responsible for the lower frequencies. Structural, electric (dielectric constant and dielectric loss) and magnetic (complex permeability and DC magnetization) properties of $\mathrm{Ca}_{1-\mathrm{x}} \mathrm{Sr}_{\mathrm{x}}\left(\mathrm{Fe}_{0.5} \mathrm{Ta}_{0.5}\right) \mathrm{O}_{3}$ are discussed in this manuscript. By these studies we specifically search for correlations between structural, magnetic, and dielectric properties, including possible magnetoelectric effects.

\section{Experimental}

\subsection{Sample Preparation}

Multiferroic Ceramic oxides $\mathrm{Ca}_{1-\mathrm{x}} \mathrm{Sr}_{\mathrm{x}}\left(\mathrm{Fe}_{0.5} \mathrm{Ta}_{0.5}\right) \mathrm{O}_{3}$, (where $x=0,0.1,0.2,0.3,0.4$ and 0.5 ) were prepared by a solid-state reaction technique. High-purity ( 99.9\%) ingredients: $\mathrm{CaCO}_{3}, \mathrm{SrCO}_{3}, \mathrm{Fe}_{2} \mathrm{O}_{3}, \mathrm{Ta}_{2} \mathrm{O}_{5}$ were used for the preparation of ceramics. These chemicals were taken in stoichiometric ratio, and mixed for $24 \mathrm{~h}$. Then the mixed powders were calcined in air at $1050^{\circ} \mathrm{C}$ for $5 \mathrm{~h}$ with a heating rate of $10^{\circ} \mathrm{C} / \mathrm{min}$ and cooling rate of $5^{\circ} \mathrm{C} / \mathrm{min}$ in a furnace to establish the course of nucleation for the grain growth and to felicitate the decomposition of the substituent oxides/carbonates. To obtain a homogeneous mixture, the calcined powder of the above mentioned ceramics were regrind. The samples were sintered at $1450^{\circ} \mathrm{C}$ for $5 \mathrm{~h}$ and then brought to room temperature

\subsection{Characterization}

The crystal structure of the prepared samples were studied using a X-ray diffractometer (BRUKER D8 ADVANCE) with $\mathrm{CuK}_{\alpha}$ radiation $(\lambda=1.541 \AA)$ at room temperature. The lattice parameters were calculated from the X-ray diffraction (XRD) data. The microstructure of the sintered samples was examined by a Field Emission Scanning Electron Microscopy (FESEM, model no. JEOL JSM $7600 \mathrm{~F}$ ). The theoretical density, $\rho_{\mathrm{x}}$ of the samples was determined by the formula,

$$
\rho_{x}=\frac{n \times M_{A}}{N_{A} V}
$$

where, $n$ is the number of atoms in a unit cell, $M_{A}$ is the molar mass of the sample, $N_{A}$ is the Avogadro's number and $V$ is the volume of the unit cell. The bulk density, $\rho_{B}$ of each sample was calculated using the relation:

$$
\rho_{B}=\frac{m}{\pi r^{2} t}
$$

where, $m$ is the mass, $r$ is the radius and $t$ is the thickness of the sample. The porosity, $P$ of the samples were calculated using the formula,

$$
P(\%)=\left[\left(\rho_{x}-\rho_{B}\right) / \rho_{x}\right] \times 100 \%
$$

The dielectric measurements were carried out at room temperature within the frequency range of $100 \mathrm{~Hz}-10 \mathrm{MHz}$ by using Wane Kerr Impedance Analyzer (series B 6500). To measure dielectric properties, the samples were painted on both sides by conducting silver paste to ensure good electrical contacts. The dielectric constant $\left(\varepsilon^{\prime}\right)$ was calculated from the capacitance using the formula: 


$$
\varepsilon^{\prime}=\frac{C t}{\varepsilon_{n} A}
$$

where, $C$ is the capacitance of the pellet, $A$ is the cross-sectional area of the electrode and $\varepsilon_{0}=8.85 \times 10^{12} \mathrm{~F} / \mathrm{m}$ is the permittivity in free space. The complex impedance spectroscopy is a powerful tool to investigate the electrical properties of the complex oxides. The main advantages of the technique are i) it involves relatively simple electrical measurements that can readily be automated, ii) the results can be often correlated with composition, microstructure, defects, dielectric properties etc. of the sample and iii) the resistance of the grain boundaries and that of grains can be easily separated in most of the polycrystalline samples. Complex impedance spectroscopy were measured using Wane Kerr Impedance Analyzer (series B 6500) in which the resistance $R$ and capacitance $C$ of the sample are measured and balanced against variable resistors and capacitors. The impedance $|Z|$ and the phase difference $(\theta)$ between the voltage and current are measured as a function of frequency for the given sample and the technique is called impedance spectroscopy. The complex modulus spectroscopy is a very convenient tool to determine, analyze and interpret the electric transport properties in the materials having the smallest capacitance. The modulus spectra are particularly useful for separating spectral components of the materials having similar resistance but different capacitance. Dielectric relaxation and conduction process also have been carried out in the complex modulus $M^{*}$ formalism. The real and imaginary parts of electric modulus were obtained from the impedance data in accordance with the relation:

$$
M^{\prime}=\varepsilon^{\prime} /\left(\varepsilon^{\prime 2}+\varepsilon^{\prime \prime 2}\right)
$$

and

$$
M^{\prime \prime}=\varepsilon^{\prime \prime} /\left(\varepsilon^{\prime 2}+\varepsilon^{\prime \prime 2}\right)
$$

The ac conductivity $\left(\sigma_{a c}\right)$ was determined at room temperature in the frequency range $100 \mathrm{~Hz}-10 \mathrm{MHz}$ to study the mechanism of conduction. For the measurement of ac conductivity the samples were painted on either side with silver paste to ensure good electric contacts. The ac conductivity of the sample was calculated from the dielectric data using the relation

$$
\sigma_{a c}=\omega \varepsilon_{0} \varepsilon^{\prime} \tan \delta
$$

Permeability is one of the most important parameters in evaluating magnetic properties. The real part $\left(\mu_{i}^{\prime}\right)$ and imaginary part $\left(\mu_{i}^{\prime \prime}\right)$ of the complex initial permeability $\left(\mu_{i}^{*}\right)$ were measured as a function of frequency within the range of $100 \mathrm{kHz}$ - $100 \mathrm{MHz}$ using a Wayne Kerr Impedance Analyzer (series 6500B). The values of $\mu_{i}^{\prime}$ and $\mu_{i}^{\prime \prime}$ were calculated using the relations:

$$
\mu_{i}^{\prime}=\frac{L_{\mathrm{s}}}{L_{\mathrm{n}}} \text { and } \mu_{i}^{\prime \prime}=\mu_{i}^{\prime} \cdot \tan \delta
$$

where, $L_{S}$ is the self inductance of the sample core and $L_{0}$ is the inductance of the winding of the coil without the sample and $\tan \delta$ is the magnetic loss. $L_{0}$ is derived from the geometrical relations, 


$$
L_{n}=\frac{\mu_{n} N^{2} S}{\pi \stackrel{n}{d}}
$$

where, $\mu_{0}$ is the permeability in vacuum, $N$ is the number of turns of the coil, $S$ is the cross-sectional area and $\bar{d}=\frac{d_{1}+d_{2}}{2}$ is the mean diameter of the toroidshaped sample, where, $d_{1}$ and $d_{2}$ are the inner and outer diameter of the toroidshaped sample, respectively.

Magnetic hysteresis is a key factor determining the possible applications of magnetic materials. $\mathrm{M}-\mathrm{H}$ curves for materials were measured using Vibrating Sample Magnetometer (VSM) (Model no.: Micro Sense EV 9), in which the sample is placed inside a uniform magnetic field to be magnetized. By physically vibrating the sample sinusoidally an induced voltage in the pickup coil is produced due to the magnetic moment which is proportional to the samples magnetization but does not depend on the strength of the applied magnetic field. Therefore by detecting the induced voltage, the magnetic-field-dependent magnetization hysteresis curve of the materials is measured.

ME effect was obtained by applying an ac magnetic field superimposed on a dc magnetic field on the sample, and then measuring the output signal with applied dc magnetic field. The sine output of the internal ac current fed to the Helmholtz coils (HC-130 turns of AWG 26 copper wire) provided ac magnetic fields of $8 \mathrm{Oe}$ at a frequency of $50 \mathrm{~Hz}$. An electromagnet was used to provide a $\mathrm{dc}$ magnetic field of up to $0.77 \mathrm{~T}$. A signal generator operating at a frequency of $50 \mathrm{~Hz}$ was used to drive the Helmholtz coil to generate an ac magnetic field. The output voltage generated from the sample under investigation was measured using a Keithley multimeter (Model 2000) as a function of dc magnetic field. ME voltage coefficient, $\alpha_{M E}$, was calculated sing relation, $\alpha_{M E}=\left(\frac{\mathrm{d} E}{\mathrm{~d} H}\right) H_{a c}=\frac{V_{0}}{h_{0} t}$, where $V_{\mathrm{o}}$ is the ME voltage across the sample surface and $h_{\mathrm{o}}$ is the amplitude of the ac magnetic field.

\section{Result and Discussions}

\subsection{XRD Analysis}

The XRD patterns of $\mathrm{Ca}_{1-\mathrm{x}} \mathrm{Sr}_{\mathrm{x}}\left(\mathrm{Fe}_{0.5} \mathrm{Ta}_{0.5}\right) \mathrm{O}_{3}$ composition sintered at $1450^{\circ} \mathrm{C}$ are shown in Figure 1. The XRD analysis confirms the $\mathrm{Ca}_{1-\mathrm{x}} \mathrm{Sr}_{\mathrm{x}}\left(\mathrm{Fe}_{0.5} \mathrm{Ta}_{0.5}\right) \mathrm{O}_{3}$ samples have the single phase simple cubic structure. The XRD peaks are well indexed to the crystal plane. The diffraction peaks of samples move to the lower angle side with the increase of $\mathrm{Sr}$ content. The systematic shift of the XRD peaks indicates the solid solubility of $\mathrm{Sr}$ in $\mathrm{Ca}\left(\mathrm{Fe}_{0.5} \mathrm{Ta}_{0.5}\right) \mathrm{O}_{3}$ lattice and the increase in lattice parameter with the increasing of $\mathrm{Sr}$ content. It is also evident that the diffraction peak for all the samples are shifted to the lower angles with the increase of $\mathrm{Sr}$ content. This may be due to the replacement of smaller $\mathrm{Ca}^{2+}(1.155 \AA)$ by the larger $\mathrm{Sr}^{2+}(1.293 \AA)$ which causes the increase of interplaner spacing between the lattices. 


\subsection{Density of the Composition}

Density and porosity play an important role in controlling the microstructure and the physical properties of the $\mathrm{Ca}_{1-\mathrm{x}} \mathrm{Sr}_{\mathrm{x}}\left(\mathrm{Fe}_{0.5} \mathrm{Ta}_{0.5}\right) \mathrm{O}_{3}$ ceramics. Figure 2 shows the theoretical density, bulk density and porosity of $\mathrm{Ca}_{1-\mathrm{x}} \mathrm{Sr}_{\mathrm{x}}\left(\mathrm{Fe}_{0.5} \mathrm{Ta}_{0.5}\right) \mathrm{O}_{3}$ ceramics sintered at $1450^{\circ} \mathrm{C}$ as a function of $\mathrm{Sr}$ content. The increase of density with the increase of $\mathrm{Sr}$ content may be attributed to the fact that the atomic weight and density of $\mathrm{Sr}$ content is larger than that of $\mathrm{Ca}$. It also appears that the value of $\rho_{B}$ for all the compositions is lower than that of the corresponding $\rho_{x}$. This may be due to the presence of pores in the bulk samples which may be formed and developed during sintering leading to a variation in bonding among the elements and making a change in interatomic distance which in turn increases the density.

\subsection{Surface Morphology}

Figure 3 shows the FESEM images of various $\mathrm{Ca}_{1-\mathrm{x}} \mathrm{Sr}_{\mathrm{x}}\left(\mathrm{Fe}_{0.5} \mathrm{Ta}_{0.5}\right) \mathrm{O}_{3}$ ceramics sintered at $1450^{\circ} \mathrm{C}$. It is observed from the micrographs that the ceramics

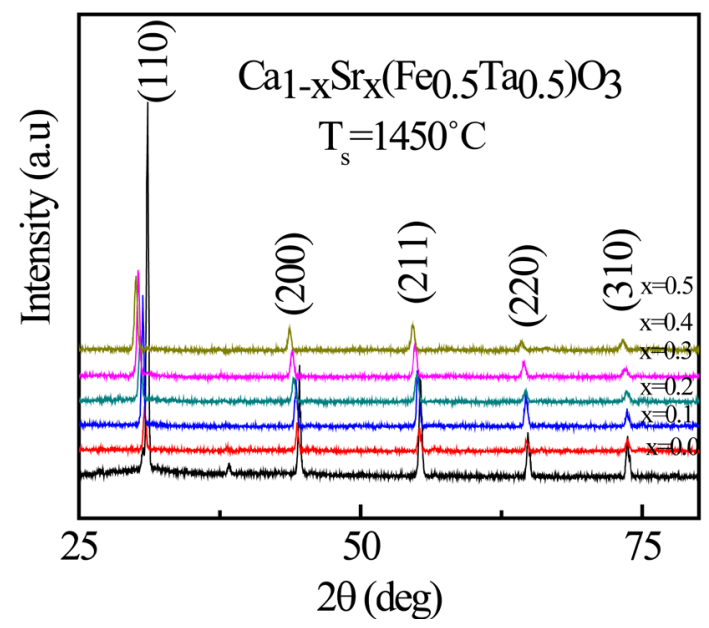

Figure 1. XRD patterns of various $\mathrm{Ca}_{1-\mathrm{x}} \mathrm{Sr}_{\mathrm{x}}\left(\mathrm{Fe}_{0.5} \mathrm{Ta}_{0.5}\right) \mathrm{O}_{3}$ sintered at $1450^{\circ} \mathrm{C}$.

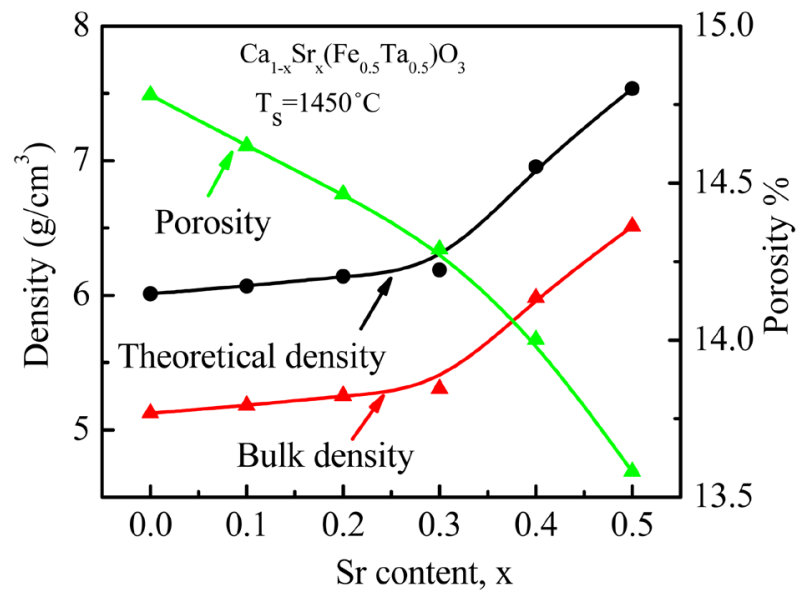

Figure 2. Variation of theoretical density, bulk density and porosity $\mathrm{Sr}$ content of various $\mathrm{Ca}_{1-\mathrm{X}} \mathrm{Sr}_{\mathrm{x}}\left(\mathrm{Fe}_{0.5} \mathrm{Ta}_{0.5}\right) \mathrm{O}_{3}$ sintered at $1450^{\circ} \mathrm{C}$. 


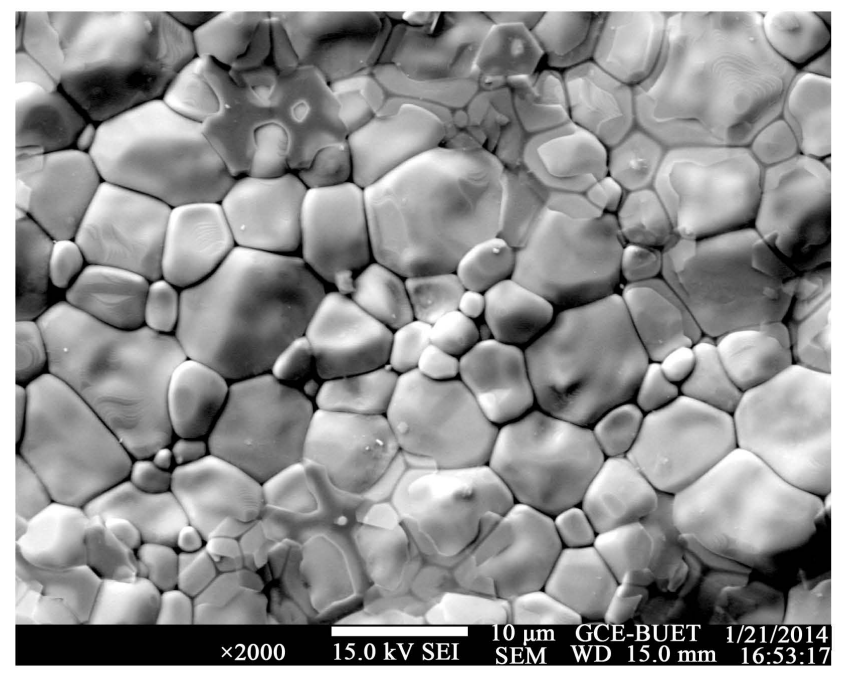

$\mathrm{X}=0.0$

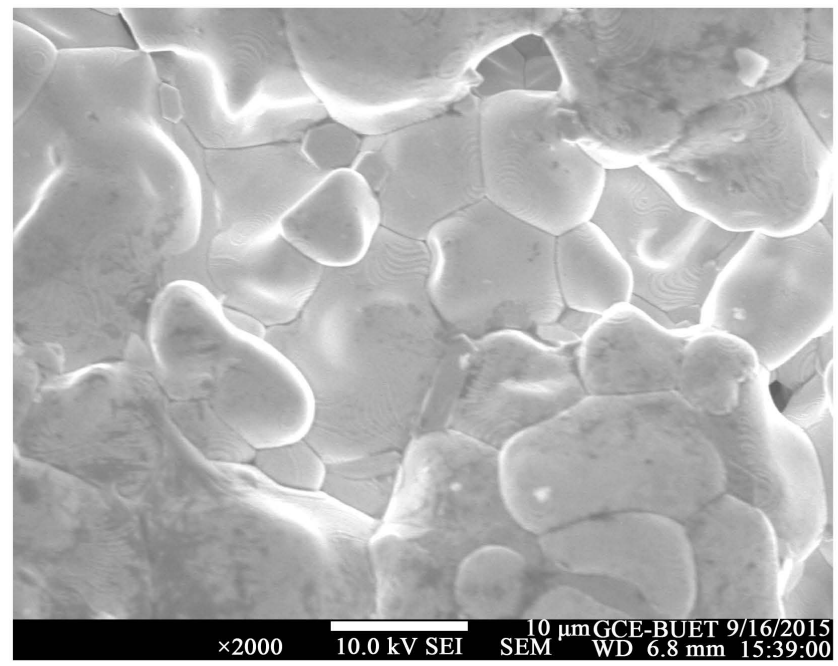

$\mathrm{X}=0.2$

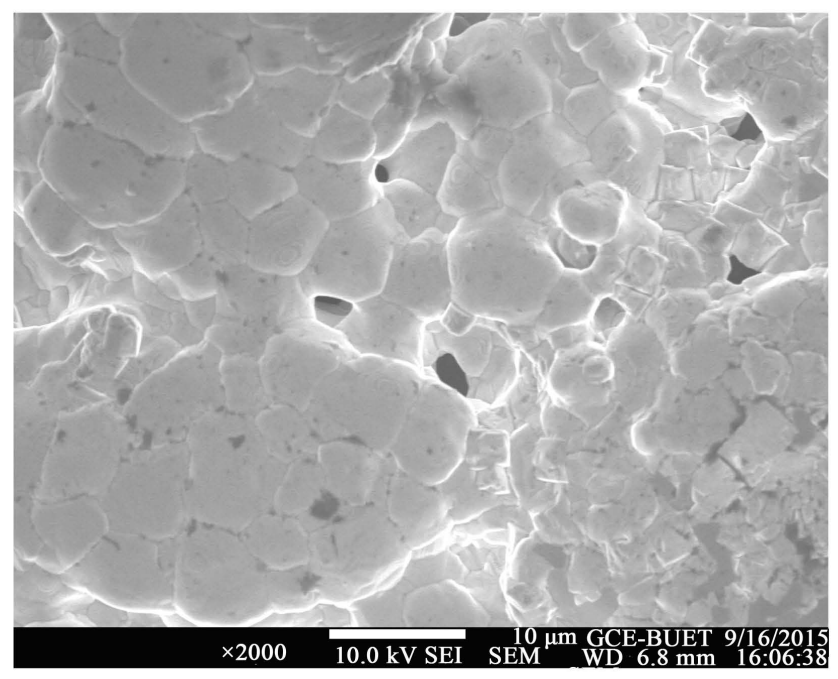

$\mathrm{X}=0.4$

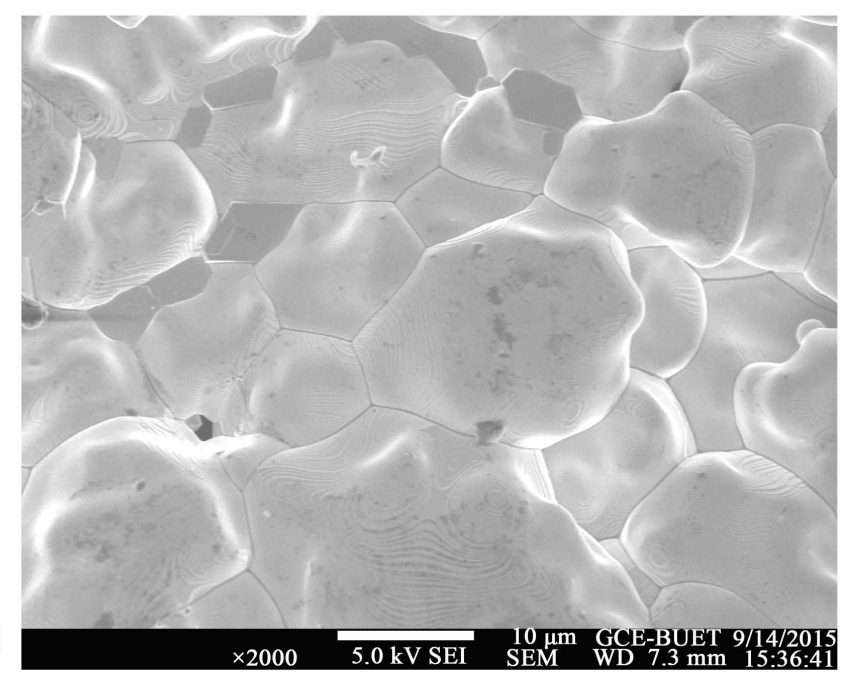

$\mathrm{X}=0.1$

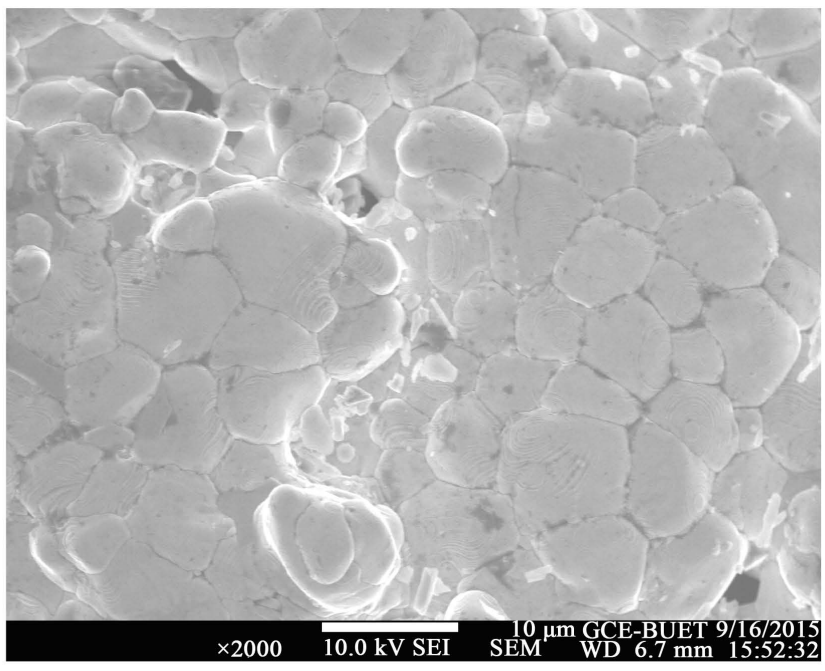

$\mathrm{X}=0.3$

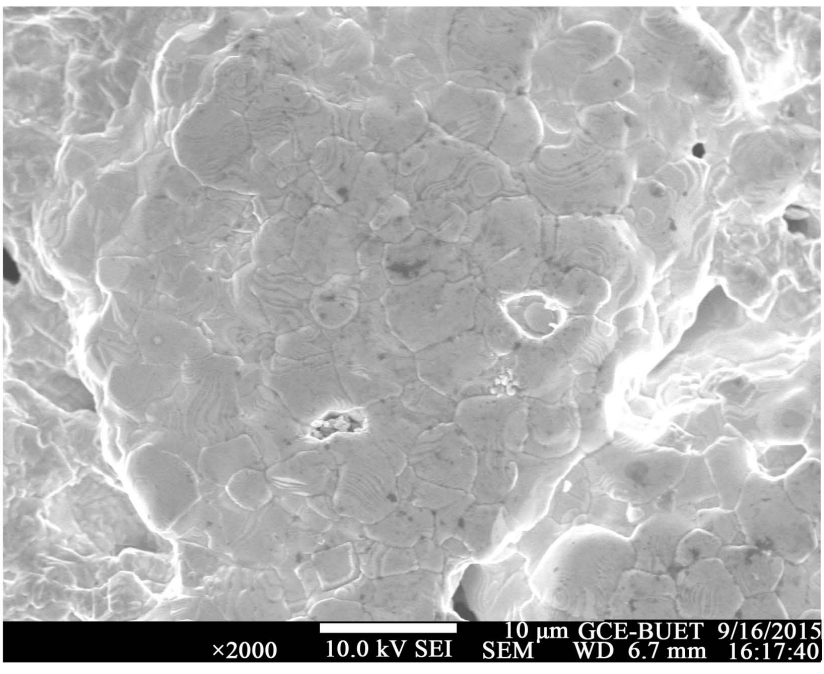

$\mathrm{X}=0.5$

Figure 3. Typical FESEM micrographs of the $\mathrm{Ca}_{1-\mathrm{S}} \mathrm{Sr}_{\mathrm{x}}\left(\mathrm{Fe}_{0.5} \mathrm{Ta}_{0.5}\right) \mathrm{O}_{3} x=0, x=0.1, x=0.2, x=0.3, x=0.4$ and $x=0.5$ sintered at $1450^{\circ} \mathrm{C}$. 
possess fine crystalline structure. The inhomogeneity in the grain size is due to the different growth rate of in the compositions. During the sintering process, the thermal energy generates a force that drives the grain boundaries to grow over pores, thereby decreasing the pore volume and increasing the density of the material. It is known that the porosity of ceramics results from two sources, such as intragranular porosity and intergranular porosity. Thus the total porosity could be written as $P=P_{\text {intra }}+P_{\text {inter }}$. The intergranular porosity mainly depends on the grain size [17].

The substitution of Sr increase the average grain size (D) till $x=0.2$ then decreases with further addition of Sr. The initial decrease in grain size may be due to the interaction of large grains with the small grains which may create a variation in the diffusion process of grain growth mechanism and further decrease is due to the stress exerted on each other. Maximum value of $\mathrm{D}$ is found to be $20.37 \mu \mathrm{m}$ for $x=0.2$. The average value of $\mathrm{D}$ is found to be in the range of 2.62 $20.37 \mu \mathrm{m}$.

\subsection{Dielectric Properties}

Figure 4 shows the variation of dielectric constant $\left(\varepsilon^{\prime}\right)$ with frequency and sintering temperatures for various $\mathrm{Ca}_{1-\mathrm{x}} \mathrm{Sr}_{\mathrm{x}}\left(\mathrm{Fe}_{0.5} \mathrm{Ta}_{0.5}\right) \mathrm{O}_{3}$ ceramics. It is seen that the value of $\varepsilon^{\prime}$ decreases with the increase in frequency. Variation of $\varepsilon^{\prime}$ with frequency also can be explained on the basis of polarization mechanisms. Polarization may be separated into three parts: dipolar, ionic and electronic. For the case of multiferroic ceramic compounds, there is another type of polarization: interfacial or space charge polarization that may originate in the materials under investigation from the point defects during sintering. At low frequency, all the types of polarization are in action but major contribution to $\varepsilon^{\prime}$ comes from space charge polarization. The space charges are able to follow the variation of the applied electric field at low frequency but at high frequency they cannot

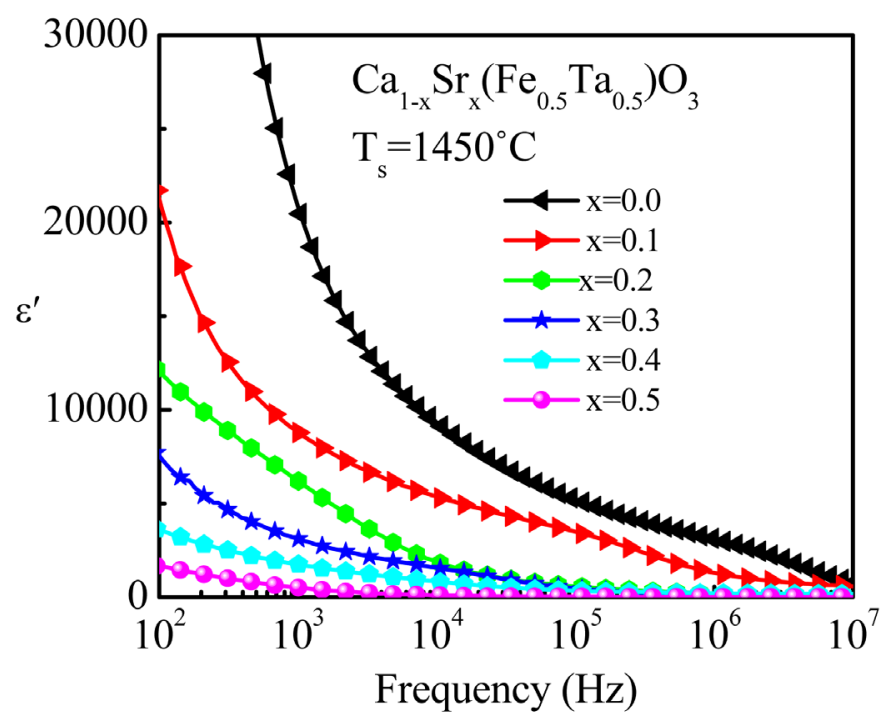

Figure 4. Variation of dielectric constant with log frequency of various $\mathrm{Ca}_{1-\mathrm{x}} \mathrm{Sr}_{\mathrm{x}}\left(\mathrm{Fe}_{0.5} \mathrm{Ta}_{0.5}\right) \mathrm{O}_{3}$ sintered at $1450^{\circ} \mathrm{C}$. 
follow the variation of field frequency. Thus contribution of space charges at high frequency towards $\varepsilon^{\prime}$ decreases. Moreover, the dipolar and the ionic contributions are also small at higher frequency due to the inertia of the molecules and ions. The value of $\varepsilon^{\prime}$ is also found decreasing with the increase in $\mathrm{Sr}$ content which might be due to the hopping mechanism of $3 \mathrm{~d}$ electrons between $\mathrm{Fe}^{2+}$ and $\mathrm{Fe}^{3+}$ also reduction of oxygen vacancies. The variation of dielectric loss ( $\tan \delta$ ) with frequency of various $\mathrm{Ca}_{1-\mathrm{x}} \mathrm{Sr}_{\mathrm{x}}\left(\mathrm{Fe}_{0.5} \mathrm{Ta}_{0.5}\right) \mathrm{O}_{3}$ ceramics is shown in Figure 5. The dielectric loss arises mainly due to impurities and imperfections in the crystal lattice. It is observed that the compositions exhibit a loss peak according to Debye relaxation theory. The electric dipoles cannot follow the alternating field instantaneously; some time is needed for the alignment of dipoles with the field.

\subsection{Complex Impedance Analysis}

Complex impedance spectroscopy is a powerful method to characterize many of the electrical properties of multiferroic ceramics and their interfaces. It may be used to explore the dynamics of mobile or bound charges in the bulk or interfacial regions. The impedance behavior is described by the classical model known as Debye model. It can also be used to do investigate the dynamics of bound or mobile charge in the bulk or interfacial regions of any kind of solid or liquid material: ionic, semiconducting, mixed electronic-ionic and even insulators (dielectrics). Figure 6 and Figure 7 show the variation of $Z^{\prime}$ and $Z^{\prime \prime}$ with frequency at room temperature for all compositions and at room temperature of various $\mathrm{Ca}_{1-\mathrm{x}} \mathrm{Sr}_{\mathrm{x}}\left(\mathrm{Fe}_{0.5} \mathrm{Ta}_{0.5}\right) \mathrm{O}_{3}$ ceramics. It is observed that the value of both $Z^{\prime}$ and $Z^{\prime \prime}$ gradually decreases with increasing frequency up to a certain limiting frequency. The decrease in $Z^{\prime}$ and $Z^{\prime \prime}$ indicate that the conduction is increasing with frequency. The higher values of $Z^{\prime}$ and $Z^{\prime \prime}$ at lower frequencies means the polarization in the relaxors is larger because at lower frequency all kinds of polarization is presented. It is also observed that these for all compositions

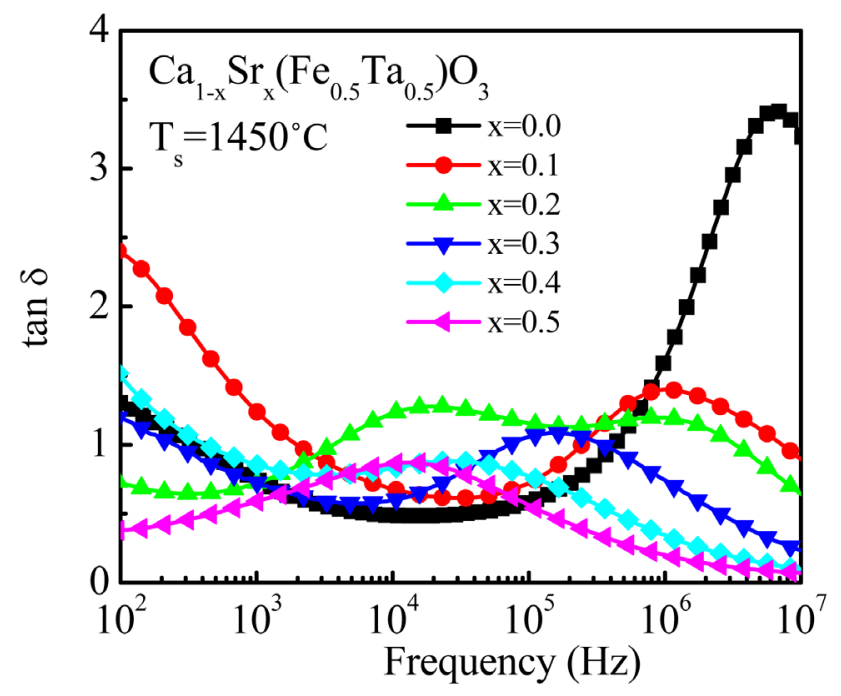

Figure 5. Variation of $\tan \delta$ with $\log$ frequency of various $\mathrm{Ca}_{1-\mathrm{x}} \mathrm{Sr}_{\mathrm{x}}\left(\mathrm{Fe}_{0.5} \mathrm{Ta}_{0.5}\right) \mathrm{O}_{3}$ sintered at $1450^{\circ} \mathrm{C}$. 


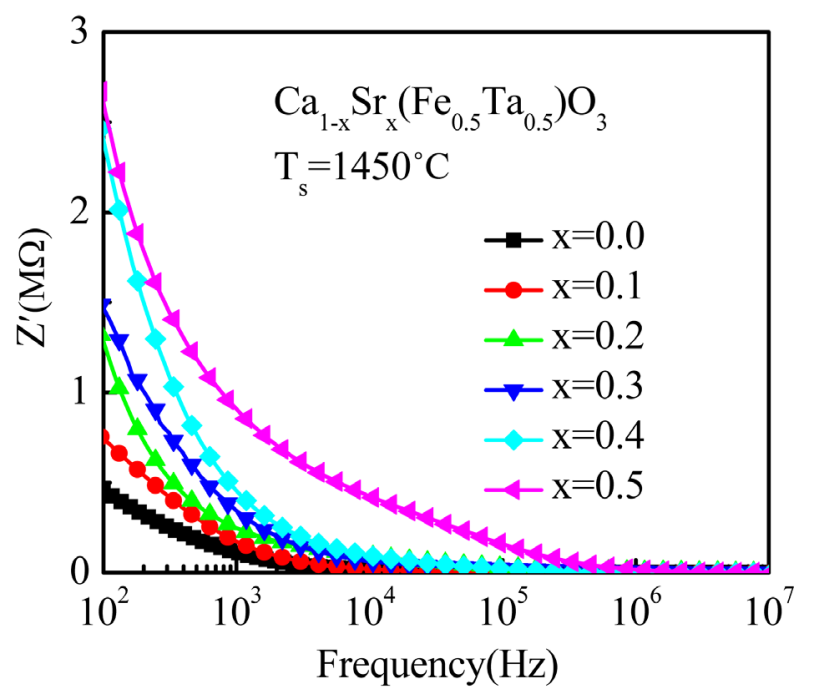

Figure 6. Variation of real part of impedance spectra $\mathrm{Z}^{\prime}$ with $\log$ frequency of various $\mathrm{Ca}_{1-\mathrm{x}} \mathrm{Sr}_{\mathrm{x}}\left(\mathrm{Fe}_{0.5} \mathrm{Ta}_{0.5}\right) \mathrm{O}_{3}$ sintered at $1450^{\circ} \mathrm{C}$.

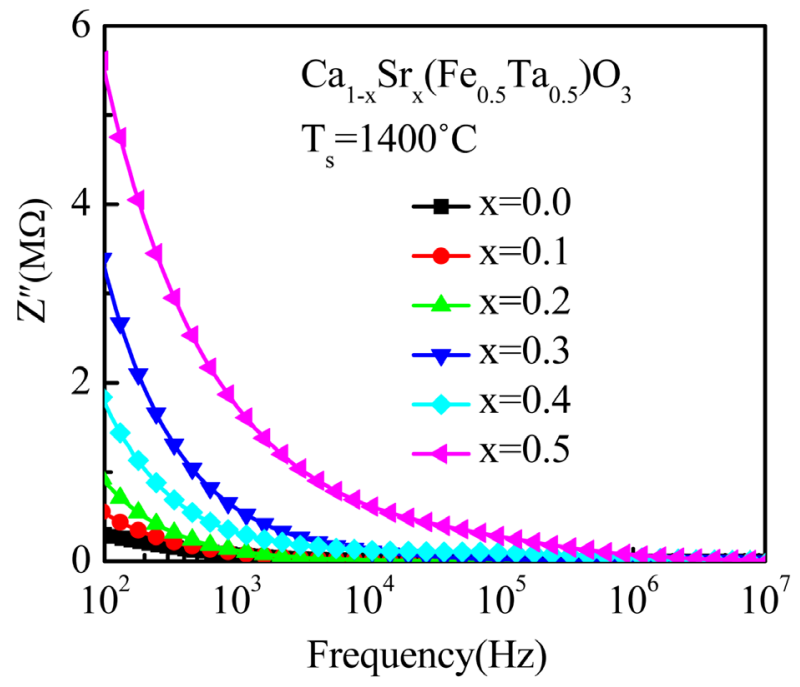

Figure 7. Variation of imaginary part of impedance spectra $Z^{\prime \prime}$ with $\log$ frequency of various $\mathrm{Ca}_{1-\mathrm{x}} \mathrm{Sr}_{\mathrm{x}}\left(\mathrm{Fe}_{0.5} \mathrm{Ta}_{0.5}\right) \mathrm{O}_{3}$ sintered at $1450^{\circ} \mathrm{C}$.

coincide at higher frequencies. The merger of $Z^{\prime}$ and $Z^{\prime \prime}$ at higher frequencies indicates possible release of space charge polarization [18] [19]. On the other hand, with increasing Sr concentration, the value of $Z^{\prime}$ and $Z^{\prime \prime}$ increases in the low frequency range and then they appear to merge in the high frequency region. This indicates that the frequency at which the space charge becomes free also depends upon the Sr concentration.

\subsection{Complex Modulus Analysis}

The complex modulus spectroscopy is a very convenient method to determine, analyze and interpret the electric transport properties in the materials having the smallest capacitance. The modulus spectra are particularly useful for separating spectral components of the materials having similar resistance but different ca- 
pacitance. The variation of real part of modulus $\left(M^{\prime}\right)$ with frequency at room temperature is shown in Figure 8. The value of $M^{\prime}$ is found to be very low at low frequencies and it increases with the increase in frequency. This continuous dispersion on increasing frequency may be contributed to the conduction phenomena due to short range mobility of charge carriers. It is possibly related to the lack of restoring force leading the mobility of the charge carriers under the action of an induced electric field [20].

Figure 9 shows the variation of imaginary part of electric modulus $\left(M^{\prime \prime}\right)$ with frequency at room temperature. It exhibits a peak at the frequency at higher frequency. These peaks indicate the transition from long-range to short range mobility of charge carriers with the increase in frequency. The frequency region below the peak maximum determines the range in which charge carriers are mobile over long distance whereas the region above peak maxima establishes the charge carriers are confined to potential well. It is also observed that the peaks

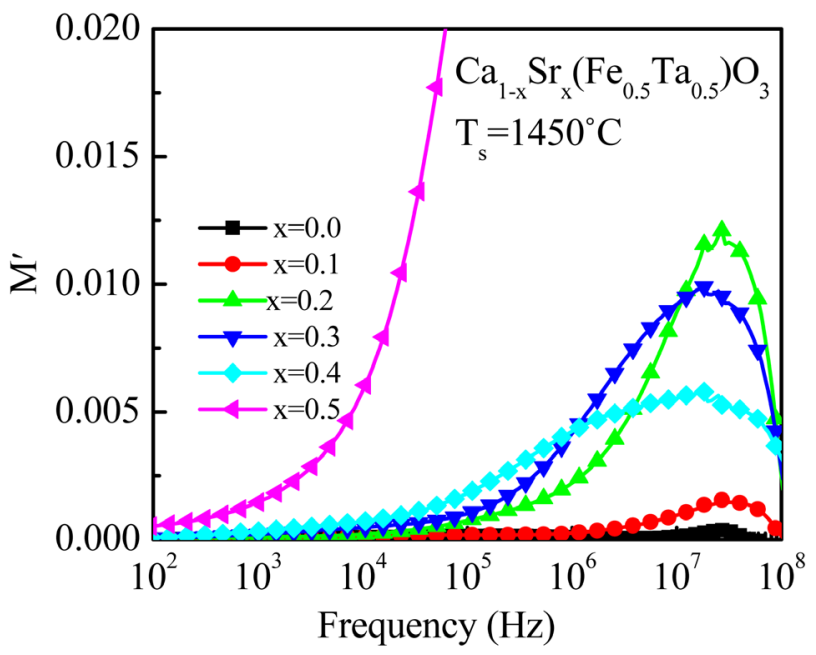

Figure 8. Variation of real part of modulus spectra $\mathrm{M}^{\prime}$ with $\log$ frequency of various $\mathrm{Ca}_{1-\mathrm{x}} \mathrm{Sr}_{\mathrm{x}}\left(\mathrm{Fe}_{0.5} \mathrm{Ta}_{0.5}\right) \mathrm{O}_{3}$ sintered at $1450^{\circ} \mathrm{C}$.

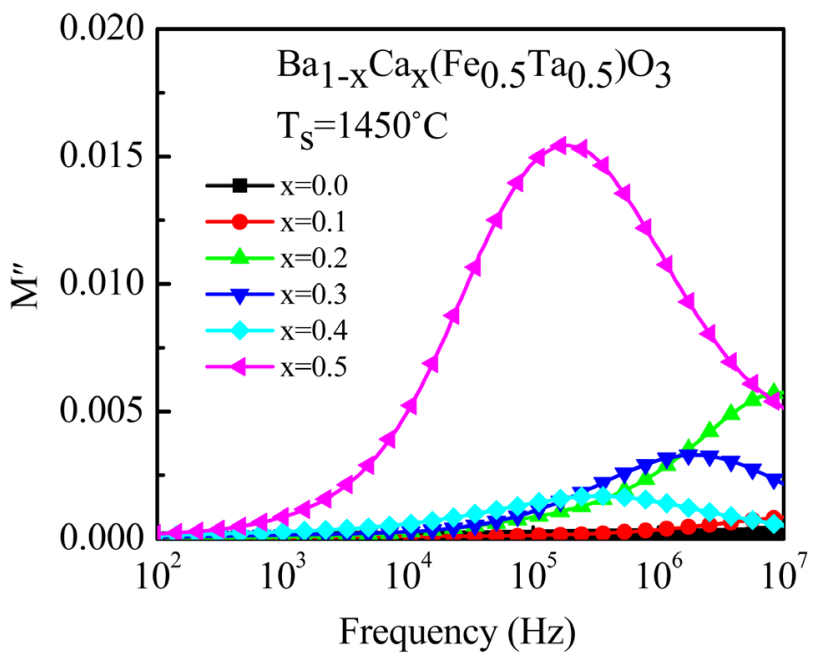

Figure 9. Variation of imaginary part of modulus spectra $\mathrm{M}^{\prime \prime}$ with $\log$ frequency of various $\mathrm{Ca}_{1-\mathrm{x}} \mathrm{Sr}_{\mathrm{x}}\left(\mathrm{Fe}_{0.5} \mathrm{Ta}_{0.5}\right) \mathrm{O}_{3}$ sintered at $1450^{\circ} \mathrm{C}$. 
are shifting towards lower frequency side with the increase in $\mathrm{Sr}$ content. This behavior indicates that the dielectric relaxation is thermally activated in this compound in which hopping mechanism of charge carriers dominate intrinsically like previous report [21]. The observed asymmetry in peak broadening indicates the spread of relaxation with different time constant and hence the relaxation in the material is of non-Debye type.

Figure 10 shows the Nyquist plots $\left(Z^{\prime \prime}\right.$ vs. $\left.Z^{\prime}\right)$ over a wide range of frequency $\left(100 \mathrm{~Hz}-10 \mathrm{MHz}\right.$ ) of $\mathrm{Ca}_{1-\mathrm{x}} \mathrm{Sr}_{\mathrm{x}}\left(\mathrm{Fe}_{0.5} \mathrm{Ta}_{0.5}\right) \mathrm{O}_{3}$ composition at room temperature to distinguish between the grain and grain boundary effects to the total resistance. In practice experimental data are only rarely found to yield a full semicircle with its center on the real axis of the complex plane. The perturbations which may still lead to at least part of a semicircular arc in the complex plane are [22]:

(i) The arc does not pass through the origin either because there are other arcs appearing at higher frequencies and/or because bulk resistance is greater than zero, (ii) The center of an experimental arc is frequently displaced below the real axis because of the presence of distributed elements in the material-electrode system (iii) Arcs can be substantially distorted by other relaxations whose mean time constants are within two orders of magnitude or less of that for the arc under consideration. The semicircle in the high frequency side represents the bulk resistance and that in the low frequency side represents the grain boundary resistance. The third semicircle or a spike in the low frequency region is also observed in some materials which is attributed to the effect of blocking electrodes [23]. This behavior can be described by an equivalent circuit consisting of two sub-circuits connected in series as shown in Figure 10.

The low and high frequency semicircular arcs correspond to the $\mathrm{R}_{\mathrm{gb}} \mathrm{C}_{\mathrm{gb}}$ and $\mathrm{R}_{\mathrm{g}} \mathrm{C}_{\mathrm{g}}$ responses, respectively. Depressed semicircular arcs are observed for all the samples both in the high and low frequency regions which indicate that non Debye-type of relaxation exists in the present samples. In the high frequency side only single asymmetric semicircular arc is observed for all the compositions due to the overlapping of the individual semicircular arcs of the two phases. If the difference of relaxation time constants is sufficiently large two semicircular arcs would be observed in the high frequency region. The diameters of the high frequency side semicircular arcs are very small than those of low frequency side semicircular arcs indicating the dominant grain boundary contribution to the total resistance. The $R_{g b}$ initially increases slowly with the content and then it rises sharply. The rise of $R_{g b}$ may be attributed to the fact that the conductive ferroelectric grains are separated by the less conductive grains thereby increasing the total $R_{g b}$. The sharp rise in $R_{g b}$ is attributed to the increased porosity of the samples. The $\mathrm{R}_{\mathrm{g}}$ is extremely low as compared to the $R_{g b}$ which indicates the conducting nature of the grain. In the present investigation it is observed that Nyquist plot for $\mathrm{Ca}_{1-\mathrm{x}} \mathrm{Sr}_{\mathrm{x}}\left(\mathrm{Fe}_{0.5} \mathrm{Ta}_{0.5}\right) \mathrm{O}_{3}$ in the low frequency region does not take the shape of a semicircle rather represents a straight line with large slope. This shows that $R_{g b}$ is out of measurement scale, which may be due to the high porosity of the sample. 


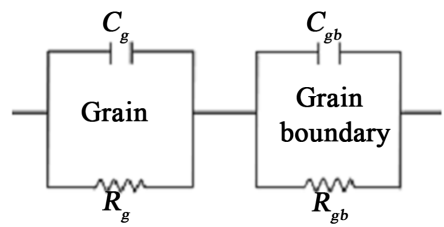

(a)

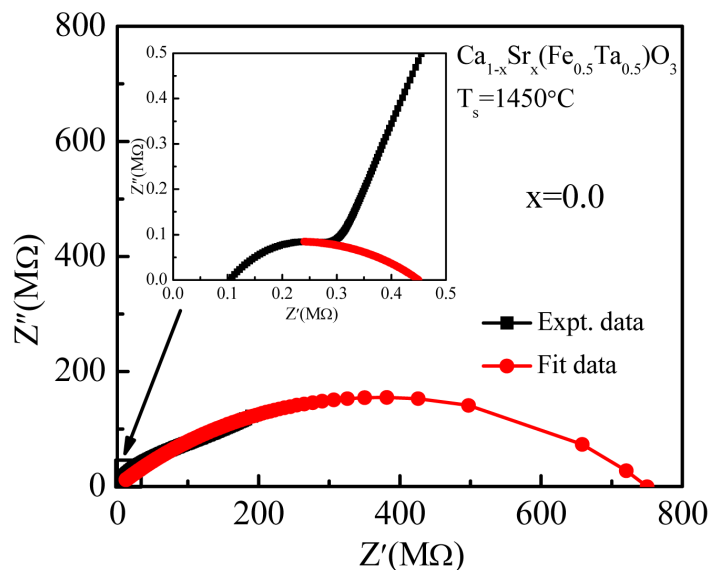

(b)

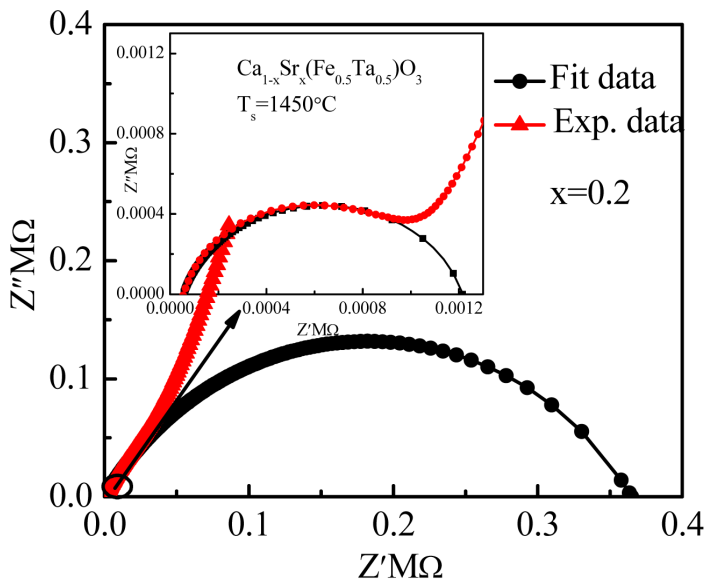

(d)

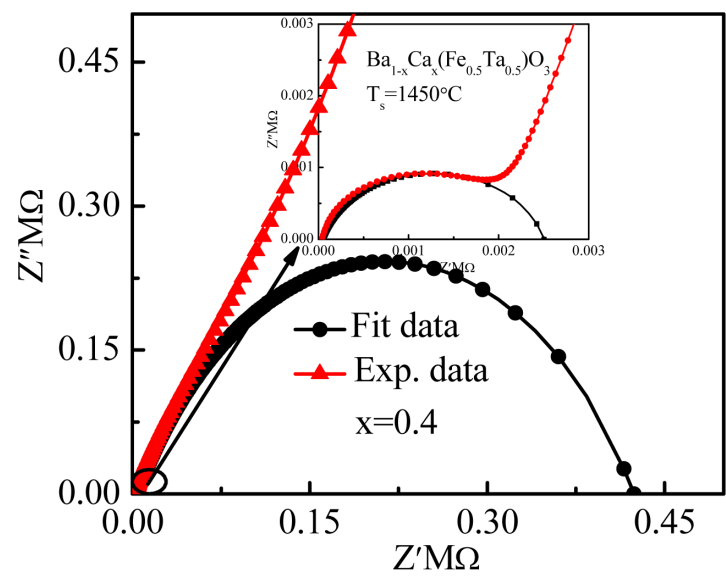

(f)

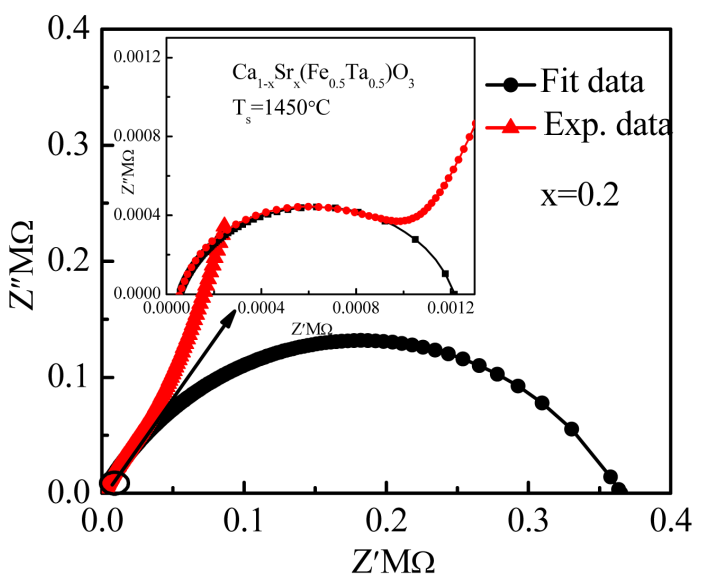

(c)

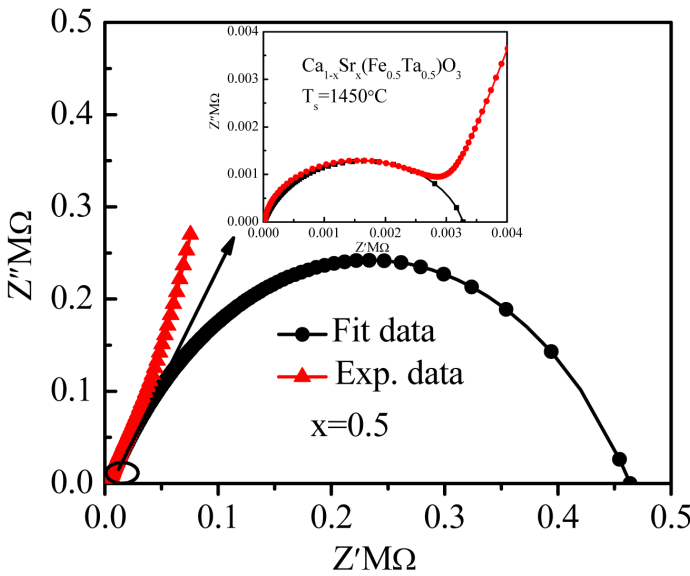

(e)

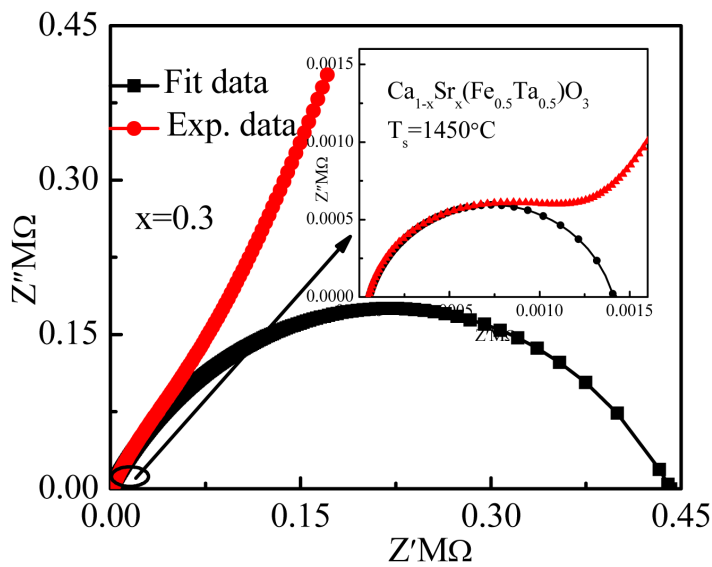

(g)

Figure 10. (a) Electrical equivalent circuit of CIS. ((b)-(f)) Nyquist plots of various $\mathrm{Ca}_{1-\mathrm{x}} \mathrm{Sr}_{\mathrm{x}}\left(\mathrm{Fe}_{0.5} \mathrm{Ta}_{0.5}\right) \mathrm{O}_{3}$ compositions sintered at $1450^{\circ} \mathrm{C}$ : (b) $x=0.0$, (c) $x=0.1$, (d) $x=0.2$, (e) $x=0.3$ (f) $x=0.4$ and (g) $x=0.5$. 


\section{7. ac Conductivity}

Conductivity plays a crucial role in $\mathrm{Ca}_{1-\mathrm{x}} \mathrm{Sr}_{\mathrm{x}}\left(\mathrm{Fe}_{0.5} \mathrm{Ta}_{0.5}\right) \mathrm{O}_{3}$. It is a vital issue in the research of materials science. Electrical conductivity reveals the essential electrical characteristics and hence clarification of its mechanism is of primary importance. Figure 11 shows the variation of ac conductivity $\left(\sigma_{a c}\right)$ with frequency of various $\mathrm{Ca}_{1-\mathrm{x}} \mathrm{Sr}_{\mathrm{x}}\left(\mathrm{Fe}_{0.5} \mathrm{Ta}_{0.5}\right) \mathrm{O}_{3}$ at room temperature. It is seen that the frequency dependence of $\sigma_{\mathrm{ac}}$ spectrum exhibit two different regions. At low frequency region, which corresponds to dc conductivity $\left(\sigma_{d c}\right)$, the conductivity is almost independent of frequency. On the other hand, at high frequency region, which is known as hopping region; $\sigma_{a c}$ increases faster than that of $\sigma_{d c}$ At higher frequencies the conductive grains become more active thereby increases hopping of charge carriers and contribute to rise in conductivity.

The variation of $\sigma_{a c}$ can be explained in terms of polaron hopping mechanism [24] among the localized states. In the large polaron model, $\sigma_{a c}$ decreases with increase of frequency, while in small polaron hopping mechanism, the $\sigma_{a c}$ with increase of frequency [24] [25]. Figure 11 also shows that $\sigma_{a c}$ increases with increasing frequency. This confirms that the conduction phenomenon in this composition is due to small polaron hopping. The variation of $\sigma_{a c}$ with frequency can also be explained on the basis of Jonscher's law [26]:

$$
\sigma_{a c}(\omega)=\sigma_{0}+A \omega^{n}
$$

where $\sigma_{a c}$ is the total conductivity, $\sigma_{0}$ is the frequency independent conductivity, and the coefficient $A$ and exponent $n(0<n<1)$ are temperature and materials intrinsic property dependent [27]. Thus the conduction process in the present composition is mainly due to small polaron hopping. According to Jonscher's law the variation of $\log \sigma_{a c}$ with $\log (\omega)$ should be linear. However, a slight deviation from linearity is attributed to mixed polarons (small/large) conduction [28]. Hopping mechanism is favored in ionic lattices in which the same kind of cataion is found in two different oxidatation states. Thus in the conduction

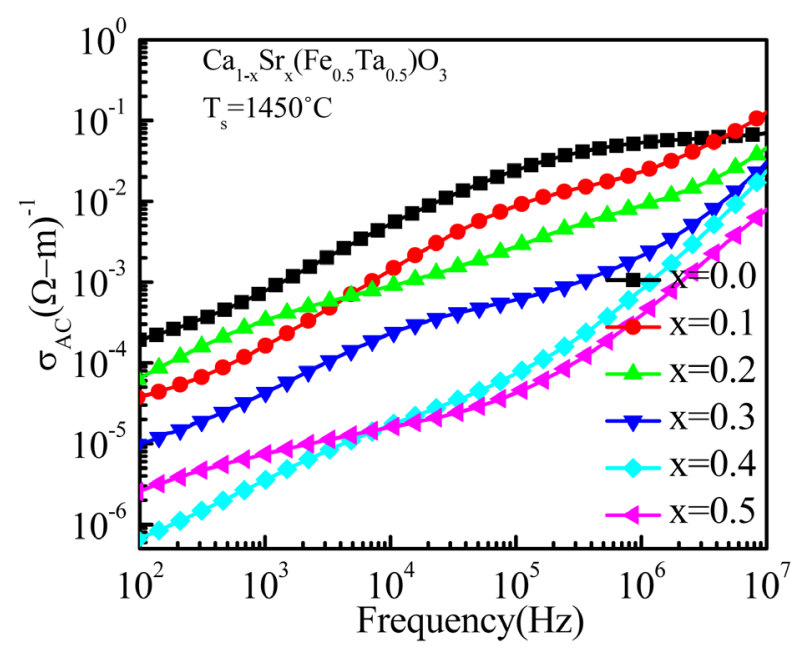

Figure 11. Variation of $\log (\sigma \mathrm{ac})$ versus $\log (f)$ of various$\mathrm{Ca}_{1-\mathrm{x}} \mathrm{Sr}_{\mathrm{x}}\left(\mathrm{Fe}_{0.5} \mathrm{Ta}_{0.5}\right) \mathrm{O}_{3}$ sintered at $1450^{\circ} \mathrm{C}$. 
process, the hopping of $3 \mathrm{~d}$ electrons between $\mathrm{Fe}^{2+}$ and $\mathrm{Fe}^{3+}$ might play an important role. The conductivity can also be explained on the basis of polaron hopping mechanism. In large polaron model, $\sigma_{a c}$ decreases with the increase of frequency while in small polaron hopping mechanism, the $\sigma_{a c}$ increases with the increase in frequency. In present investigation, all compositions exhibit an increase in conductivity with frequency which indicates that small polaron hopping is present in the conduction mechanism of the studied compound.

\subsection{Complex Initial Permeability}

The complex initial permeability is given by

$$
\mu_{i}^{*}=\mu_{i}^{\prime}-\mu_{i}^{\prime \prime}
$$

$\mu_{i}^{\prime}$ describes the stored energy expressing the component of magnetic induction $B$ in phase with the alternating magnetic field $H . \quad \mu_{i}^{\prime \prime}$ describes the dissipation of energy expressing the out of phase component of $\mathrm{B}$.

Figure 12 shows the variation of real part initial permeability $\left(\mu_{i}^{\prime}\right)$ with frequency for various $\mathrm{Ca}_{1-\mathrm{x}} \mathrm{Sr}_{\mathrm{x}}\left(\mathrm{Fe}_{0.5} \mathrm{Ta}_{0.5}\right) \mathrm{O}_{3}$ within the range of $100 \mathrm{kHz}-100 \mathrm{MHz}$ at room temperature. The value of real part of permeability $\left(\mu_{i}^{\prime}\right)$ for all the compositions remains constant up to certain frequency and then decreases with increasing frequency. It is also seen from the figure that the value of $\mu_{i}^{\prime}$ is increasing with $\mathrm{Sr}$ content and then gradually decreases. Permeability in magnetic materials originates because of the spin rotation and domain wall motion which is due to the fact that at higher frequencies, pinning points are found to be originated at the surface of the samples from the impurities of grains and intragranular pores. This phenomenon in turn obstructs the motion of spin and domain walls and the contribution of their motion towards the increment of permeability decreases [29]. On the other hand, it is difficult to explain compositional dependence of $\mu_{i}^{\prime}$ for the case of polycrystalline materials because $\mu_{i}^{\prime}$ is sensitive to many factors. The value of $\mu_{i}^{\prime}$ depends on stoichiometry, composition,

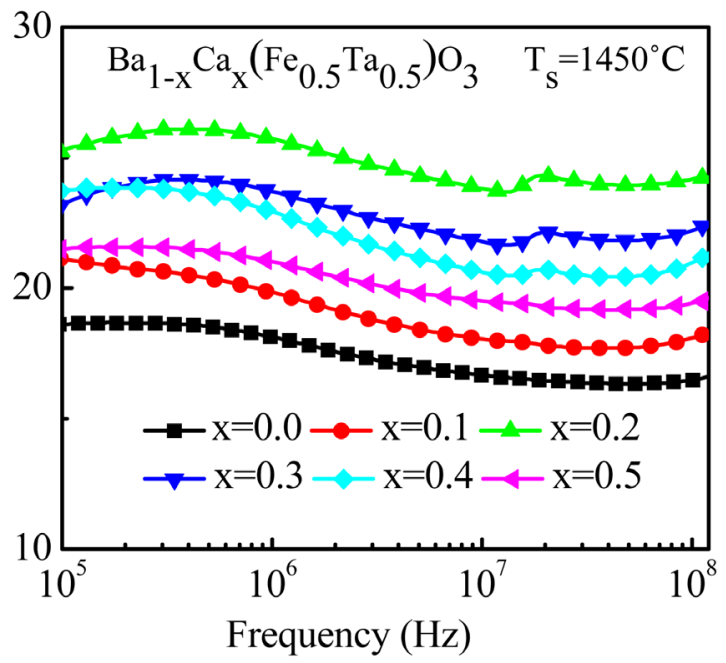

Figure 12. Variation of $\mu_{i}^{\prime}$ as a function of frequency of various $\mathrm{Ca}_{1-\mathrm{x}} \mathrm{Sr}_{\mathrm{x}}\left(\mathrm{Fe}_{0.5} \mathrm{Ta}_{0.5}\right) \mathrm{O}_{3}$ sintered $1450^{\circ} \mathrm{C}$. 
average grain size, impurity, coercivity, porosity etc. The $\mu_{i}^{\prime}$ remains almost constant over the whole frequency range. Figure 13 shows the variation of RQF with frequency for various $\mathrm{Ca}_{1-\mathrm{x}} \mathrm{Sr}_{\mathrm{x}}\left(\mathrm{Fe}_{0.5} \mathrm{Ta}_{0.5}\right) \mathrm{O}_{3}$ within the range of $100 \mathrm{kHz}$ $100 \mathrm{MHz}$ at room temperature as loss is decreasing with increasing frequency. The loss is mainly due to mainly due to the phase lag of domain wall motion with respect to the applied field.

\subsection{Magnetic Hysteresis}

Magnetic hysteresis is a key factor determining the possible applications of magnetic materials. The magnetization as a function of applied magnetic field for various $\mathrm{Ca}_{1-\mathrm{x}} \mathrm{Sr}_{\mathrm{x}}\left(\mathrm{Fe}_{0.5} \mathrm{Ta}_{0.5}\right) \mathrm{O}_{3}$ composition sintered at $1450^{\circ} \mathrm{C}$ shown in Figure 14 The magnetization of all the samples increases sharply with increasing

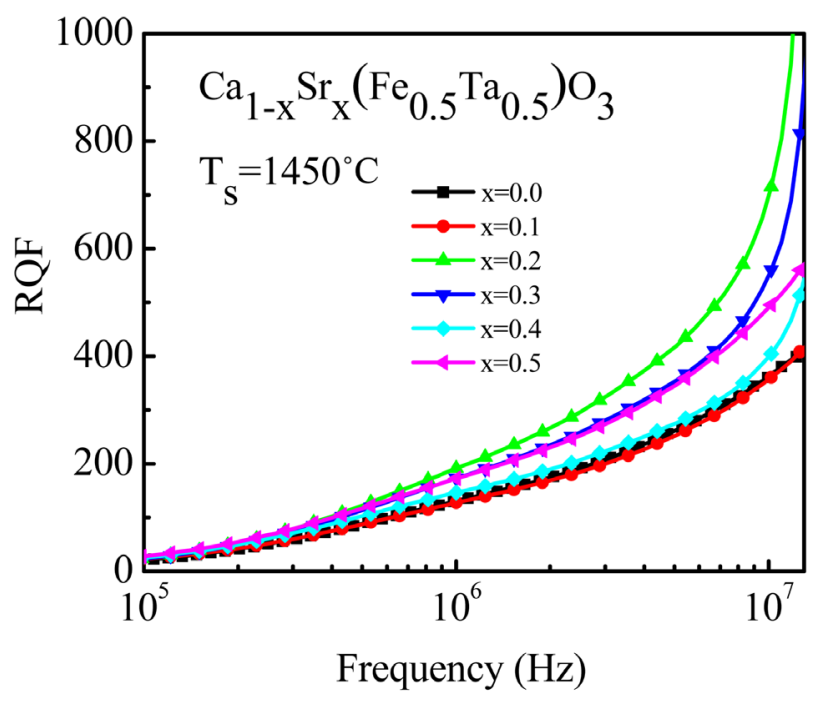

Figure 13. Variation of RQF as a function of frequency of various $\mathrm{Ca}_{1-\mathrm{x}} \mathrm{Sr}_{\mathrm{x}}\left(\mathrm{Fe}_{0.5} \mathrm{Ta}_{0.5}\right) \mathrm{O}_{3}$ sintered at $1450^{\circ} \mathrm{C}$.

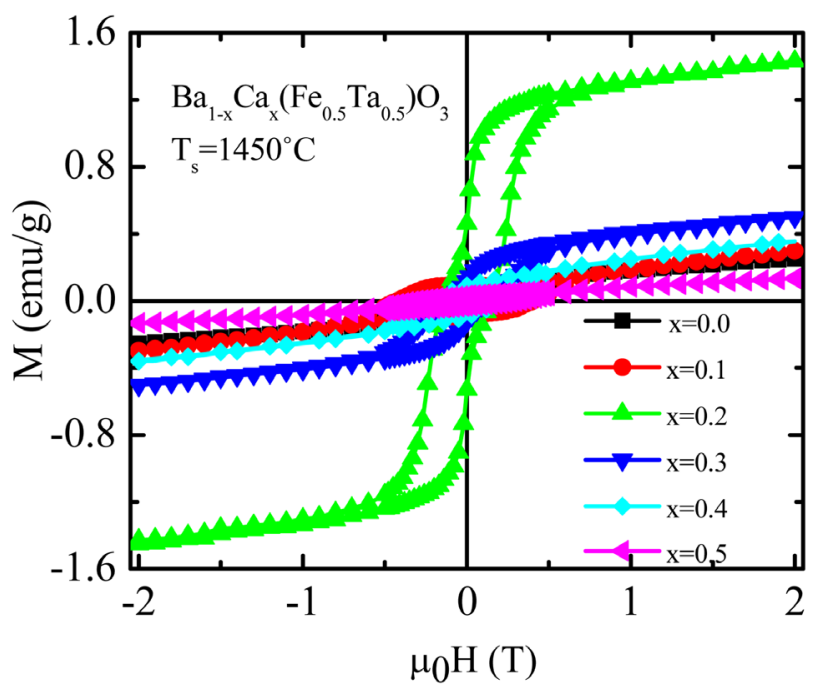

Figure 14. $\mathrm{M}-\mathrm{H}$ hysteresis loops of various $\mathrm{Ca}_{1-\mathrm{x}} \mathrm{Sr}_{\mathrm{x}}\left(\mathrm{Fe}_{0.5} \mathrm{Ta}_{0.5}\right) \mathrm{O}_{3}$ ceramics sintered at $1450^{\circ} \mathrm{C}$ measured at room temperature. 
applied field up to $0.5 \mathrm{~T}$ (in $\mu_{0} \mathrm{H}$ ). Beyond this applied field, the magnetization increases slowly and then saturation occurs. Therefore, it is clear that all the samples are in ferromagnetic at room temperature. It is seen that the saturation magnetization $\left(\mathrm{M}_{\mathrm{s}}\right)$ increases for $x=0.2$ and then decreases with increasing $\mathrm{Sr}$ content. These results are well supported by the permeability and as well as grain size. $M_{s}$ is also influenced by extrinsic factors such as microstructure and the density of the ceramics. Magnetization is known to increase with density. As the grain size increases formation of domain walls become possible and magnetization increases due to domain wall movement under the action of the magnetic field. Thus overall value of the magnetization obtained is a result of the contribution for all the factors depending upon the composition.

The remnant magnetization $\left(M_{r}\right)$ is found to be 0.030 to $0.461 \mathrm{emu} / \mathrm{g}$ showing an increment of $\mathrm{M}_{\mathrm{r}}$ up to $\mathrm{x}=0.2$ and then gradually decreases. The highest value of $\mathrm{M}_{\mathrm{r}}$ is found to be $0.461 \mathrm{emu} / \mathrm{g}$ sintered for $1450^{\circ} \mathrm{C}$ for $\mathrm{x}=0.2$ content. The values of $M_{r}$ are relatively very small as compared to other ferromagnetic compounds. Unsaturated $\mathrm{M}-\mathrm{H}$ behavior and small remnant magnetization is the indication of weak ferromagnetism [30]. The Sr substitution may suppress and could not destroy the spiral spin structure completely. Substitution of $\mathrm{Ta}^{5+}$ in $\mathrm{B}$ site may affect statistical distribution of $\mathrm{Fe}^{3+}$ in magnetic sub lattice in which local ferromagnetic structure may form between $\mathrm{Fe}^{3+}$ and $\mathrm{Ta}^{5+}$ and lead to bulk magnetization. The magnetization is found to reduce with further increase in Sr concentration because of the paramagnetic behavior of $\mathrm{Sr}$ which indicate amount of $\mathrm{Sr}$ concentration is important for the enhancement of magnetic properties.

\subsection{Magnetoelectric Properties}

The electrical control of magnetization or magnetic control of electric polarization in the solid state is significant both fundamentally and practically. In the present case, the ME effect results from the interaction between different orderings. The ME effect in multiferroic materials arises due to the interaction of the magnetic and ferroelectric domains [30]. The ME coefficient $\left(\alpha_{M E}\right)$ has been determined by dynamic method [31] with simultaneous application of ac as well as dc magnetic field. The variation of $\alpha_{M E}$ with applied dc magnetic field for all compositions is shown in Figure 15. From the figure, it is observed that $\alpha_{M E}$ decreases with increasing magnetic field. The magnetization has been observed for $\mathrm{Ca}_{1-\mathrm{x}} \mathrm{Sr}_{\mathrm{x}}\left(\mathrm{Fe}_{0.5} \mathrm{Ta}_{0.5}\right) \mathrm{O}_{3}$ which may be attributed to a large ME coupling to be present in the samples at room temperature. Sr added samples may have improved ME coupling because of better piezoelectric properties of $\mathrm{Ca}_{1-\mathrm{x}} \mathrm{Sr}_{\mathrm{x}}\left(\mathrm{Fe}_{0.5} \mathrm{Ta}_{0.5}\right) \mathrm{O}_{3}$. This initial rise in $\alpha_{M E}$ may be attributed to the enhancement in elastic interaction. Applied magnetic field induces large strain in magnetic domains of the samples. Due to the coupling of the magnetic and ferroelectric domains the strain produces stress (strain mediated stress) in ferroelectric domains. The stress causes an increase in polarization of the ferroelectric domains and at a certain amount of Sr the electric polarization becomes easier due to better 


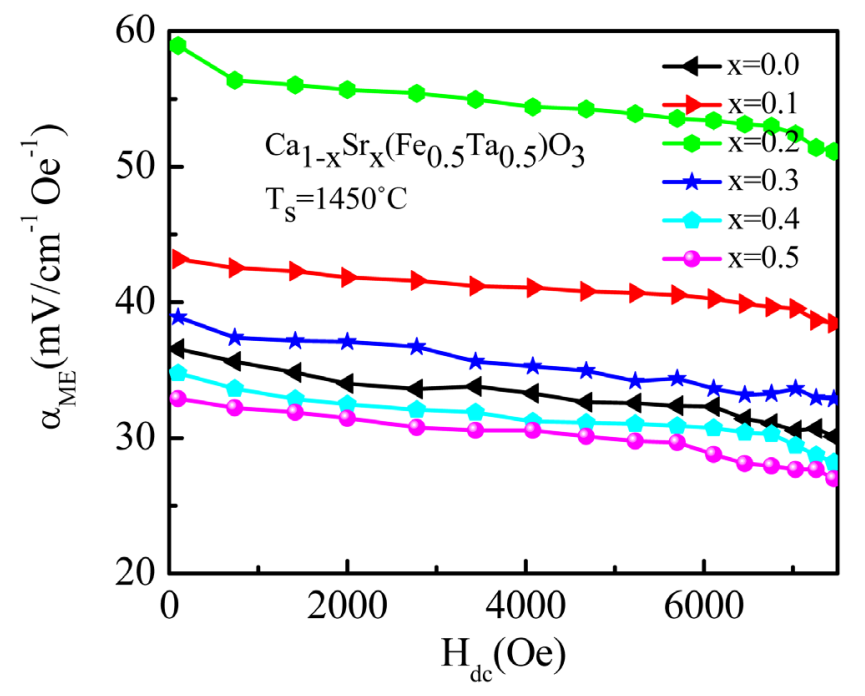

Figure 15. Variation of $\alpha \mathrm{ME}$ with magnetic field of various $\mathrm{Ca}_{1-\mathrm{x}} \mathrm{Sr}_{\mathrm{x}}\left(\mathrm{Fe}_{0.5} \mathrm{Ta}_{0.5}\right) \mathrm{O}_{3}$ ceramics at sintered $1450^{\circ} \mathrm{C}$.

piezoelectric properties as a result more bound charges to be appeared. These charges will help to develop more voltage in the grain which in turn produces strong ME coupling. The decrease in $\alpha_{M E}$ with the increase in magnetic field may be due to the fact that the magnetization reaches its forced saturation and hence the magnetization and associated strain produce a constant electric field in the ferroelectric phase beyond the saturation limit. This leads to a decrease in $\alpha_{M E}$ at higher magnetic fields. The decrease of $\alpha_{M E}$ may be attributed to the increased porosity in the sample. The presence of the pores breaks the magnetic contacts between the grains. Hence increase in porosity may reduce the net magnetization in the bulk and affects on magnetoelectric interactions in the compositions. The maximum $\alpha_{M E}$ is found to be 65.05 for the composition $x=0.2$.

\section{Conclusion}

Various $\mathrm{Ca}_{1-\mathrm{x}} \mathrm{Sr}_{\mathrm{x}}\left(\mathrm{Fe}_{0.5} \mathrm{Ta}_{0.5}\right) \mathrm{O}_{3}$ ceramics were synthesized by the standard solid state reaction method. The X-ray diffraction result indicates that all samples are of single phase cubic perovskite structure. The theoretical density $\left(\rho_{t h}\right)$ and the bulk density $\left(\rho_{B}\right)$ increase with increasing Sr content. The values of $\rho_{t h}$ are found to be higher than those of $\rho_{B}$. The value of average grain size was found to be changed with the increase of $\mathrm{Sr}$ content. The value of dielectric constant $\left(\varepsilon^{\prime}\right)$ for all the compositions was found to be high at lower frequencies, but it increased with the increase in frequency. However, dielectric loss is found to have higher values at lower and higher frequencies for all the compositions. The complex impedance spectroscopy is used to distinguish between the grain and grain boundary contribution to the total resistance. Asymmetric semicircular arcs observed in the Cole-Cole plots indicate that non Debye-type of relaxation exists in the present samples. The $R_{g}$ is extremely low as compared to $R_{g b}$ which indicates the conducting nature of the grain. Both the ac conductivity and modulus study reveal hopping type of conduction in the present samples. The real part of initial 
permeability $\left(\mu_{i}^{\prime}\right)$ increases with Sr content up to $x=0.2$ and then decreases with increasing $\mathrm{Sr}$ content. The maximum values of saturation and remnant magnetization were found to be $1.431 \mathrm{emu} / \mathrm{g}$ and $0.461 \mathrm{emu} / \mathrm{g}$. The highest value of $\alpha_{M E}$ is found to be $58.93 \mathrm{mV} / \mathrm{cm}^{-1} \mathrm{Oe}^{-1}$. The $\mathrm{ME}$ results imply that the composition of $\mathrm{Ca}_{1-\mathrm{x}} \mathrm{Sr}_{\mathrm{x}}\left(\mathrm{Fe}_{0.5} \mathrm{Ta}_{0.5}\right) \mathrm{O}_{3}$ may have potential applications as multiferroic materials in the future and it may be helpful for better understanding the intrinsic ME coupling and searching high-performance multiferroic ceramics and can potentially be used for fabrication of multifunctional devices such as ME transducers, actuators, sensors and heterogeneous read/write devices.

\section{Acknowledgements}

The authors greatly acknowledge the CASR, Bangladesh University of Engineering and Technology (BUET) to provide financial support for this investigation.

\section{References}

[1] Cheong, S.W. and Mostovoy, M. (2007) Multiferroics: A Magnetic Twist for Ferroelectricity. Nature Materials, 6, 13-20. https://doi.org/10.1038/nmat1804

[2] Mostovoy, M. (2006) Ferroelectricity in Spiral Magnets. Physical Review Letters, 96, Article ID: 067601.

[3] Debye, P. (1926) Bemerkung zu einigen neuen Versuchen über einen magnetoelektrischen Richteffekt. Zeitschrift für Physik, 36, 300-301.

[4] Astrov, D. (1960) The Magnetoelectric Effect in Antiferromagnetics. Soviet Physics, 11,708 .

[5] Fiebig, M. (2005) Revival of the Magnetoelectric Effect. Journal of Physics D: Applied Physics, 38, R123. https://doi.org/10.1088/0022-3727/38/8/R01

[6] Tokura, Y. (2006) Multiferroics as Quantum Electromagnets. Science, 312, 1481 1482. https://doi.org/10.1126/science.1125227

[7] Eerenstein, W., Mathur, N.D. and Scott, J.F. (2006) Multiferroic and Magnetoelectric Materials. Nature, 442, 759-765.

[8] Hill, N.A. (2000) Why Are There So Few Magnetic Ferroelectrics? The Journal of Physical Chemistry B, 104, 6694-6709. https://doi.org/10.1021/jp000114x

[9] Xin, L., Liu, X.Q., Zhao, H.J., Yang, W.Z. and Chen X.M. (2013) Dielectric and Magnetic Properties of $\operatorname{Sr}\left(\mathrm{Fe}_{1 / 2} \mathrm{Ta}_{1 / 2}\right) \mathrm{O}_{3}$ Complex Perovskite Ceramics. Journal of the American Ceramic Society, 96, 1188-1192. https://doi.org/10.1111/jace.12162

[10] Dutta, A., Bharti, C. and Sinha, T.P. (2008) AC Conductivity and Dielectric Relaxation in $\mathrm{CaMg}_{1 / 3} \mathrm{Nb}_{2 / 3} \mathrm{O}_{3}$. Materials Research Bulletin, 43, 1246-1254.

https://doi.org/10.1016/j.materresbull.2007.05.023

[11] Kumar, M. and Yadav, K.L. (2007) Rapid Liquid Phase Sintered Mn Doped $\mathrm{BiFeO}_{15}$ Ceramics with Enhanced Polarization and Weak Magnetization. Physical Review Letters, 91, Article ID: 242901. https://doi.org/10.1063/1.2816118

[12] Saha, S. and Sinha, T.P. (2002) Structural and Dielectric Studies of $\mathrm{BaFe}_{0.5} \mathrm{Nb}_{0.5} \mathrm{O}_{3}$. Journal of Physics. Condensed Matter, 14, 249-258. https://doi.org/10.1088/0953-8984/14/2/311

[13] Kobayashi, W. and Terasaki, I. (2003) Unusual Impurity Effects on the Dielectric Properties of $\mathrm{CaCu}_{3-\mathrm{x}} \mathrm{Mn}_{\mathrm{x}} \mathrm{Ti}_{4} \mathrm{O}_{12}$. Physica B: Condensed Matter, 329-333, 771-772. 
https://doi.org/10.1016/S0921-4526(02)02517-6

[14] Chung, S.-Y., Choi, S.-Y., Yamamoto, T., Ikuhara, Y. and Kang, S.-J.L. (2006) Site-Selectivity of 3d Metal Cation Dopants and Dielectric Response in Calcium Copper Titanate. Applied Physics Letters, 88, Article ID: 091917. https://doi.org/10.1063/1.2179110

[15] Li, M., Feteira, A., Sinclair, D.C. and West, A.R. (2006) Influence of Mn Doping on the Semiconducting Properties of $\mathrm{CaCu}_{3} \mathrm{Ti}_{4} \mathrm{O}_{12} \mathrm{CaCu}_{3} \mathrm{Ti}_{4} \mathrm{O}_{12}$ Ceramics. Applied Physics Letters, 88, Article ID: 232903. https://doi.org/10.1063/1.2200732

[16] Grubbs, R.K., Venturini, E.L., Clem, P.G., Richardson, J.J., Tuttle, B.A. and Samara, G.A. (2005) Dielectric and Magnetic Properties of Fe- and Nb-Doped $\mathrm{CaCu}_{3} \mathrm{Ti}_{4} \mathrm{O}_{12}$. Physical Review B, 72, Article ID: 104111. https://doi.org/10.1103/PhysRevB.72.104111

[17] Rezlescu, N., Rezlescu, E., Pasnicu, C. and Craus, M.L. (1994) Effect on Rare Earth Ions on Some Properties of Nickel Zinc Ferrite. Journal of Physics: Condensed Matter, 6, 5707-5712.

[18] Behera, B., Nayak, P. and Choudhary, R.N.P. (2008) Structural and Electrical Properties of $\mathrm{KCa}_{2} \mathrm{Nb}_{5} \mathrm{O}_{15}$ Ceramics. Central European Journal of Physics, 6, 289-295.

[19] Plocharski, J. and Wieczoreck, W. (1988) Electrochemical Stability and Ionic Conductivity of Some Polymerlic Based Electrolytes. Solid State Ionics, 28-30, 979-983.

[20] Macedo, P.B., Moynihan, C.T. and Bose, R. (1972) The Conductivity of the Super Ionic Glass Samples Increases after Irradiation and Conductors. Physics and Chemistry of Glasses, 13, 171-179.

[21] Ranjan, R., Kumar, R., Kumar, N., Behera, B. and Choudhary, R.N.P. (2011) Impedance and Electric Modulus Analysis of Sm-Modified $\mathrm{Pb}\left(\mathrm{Zr}_{0.55} \mathrm{Ti}_{0.45}\right)_{1-\mathrm{x} / 4} \mathrm{O}_{3} \mathrm{Ce}$ ramics. Journal of Alloys and Compounds, 509, 6388-6394. https://doi.org/10.1016/j.jallcom.2011.03.003

[22] Verma, K., Kumar, A. and Varshney, D. (2012) Dielectric Relaxation Behavior of $\mathrm{A}_{\mathrm{x}} \mathrm{Co}_{1-\mathrm{x}} \mathrm{Fe}_{2} \mathrm{O}_{4}(\mathrm{~A}=\mathrm{Zn}, \mathrm{Mg})$ Mixed Ferrites. Journal of Alloys and Compounds, 526, 91-97. https://doi.org/10.1016/j.jallcom.2012.02.089

[23] Kumar, D.A., Selvasekarapandian, S., Nithya, H. Sakunthala, A. and Hema, M. (2010) Dielectric, Modulus and Impedance Analysis, of $\mathrm{LaF}_{3}$ Nanoparticles. Physica B: Condensed Matter, 405, 3803-3807. https://doi.org/10.1016/j.physb.2010.06.004

[24] Adler, D. and Feinlein, J. (1970) Electrical and Optical Properties of Narrow-Band Materials. Physical Review B, 2, 3112-3134. https://doi.org/10.1103/PhysRevB.2.3112

[25] Austin, I.G. and Mott, N.F. (1969) Polarons in Crystalline and Non Crystalline Materials. Advances in Physics, 18, 41-102. https://doi.org/10.1080/00018736900101267

[26] Jonscher, A.K. (1977) The Universal Dielectric Response. Nature, 267, 673-679. https://doi.org/10.1038/267673a0

[27] Upadhyay, S., Sahu, A.K., Kumaar, D. and Parkash, O. (1998) Probing Electrical Conduction Behavior of $\mathrm{BaSnO}_{3}$. Journal of Applied Physics, 84, 828. https://doi.org/10.1063/1.368143

[28] Kadam, S.L., Patankar, K.K., Kanamadi, C.M. and Chougule, B.K. (2004) Electrical Conduction and Magnetoelectric Effect in $\mathrm{Ni}_{0.5} \mathrm{Co}_{0.5} \mathrm{Fe}_{2} \mathrm{O}_{4}+\mathrm{Ba}_{0.8} \mathrm{~Pb}_{0.2} \mathrm{TiO}_{3}$ Composite. Materials Research Bulletin, 39, 2265-2272. https://doi.org/10.1016/j.materresbull.2004.07.021

[29] Globus, A., Duplex, P. and Guyot, M. (1971) Determination of Initial Magnetization Curve from Crystallites Size and Effective Anisotropy Field. IEEE Transactions on 
Magnetics, 7, 617-622. https://doi.org/10.1109/TMAG.1971.1067200

[30] Kumar, M.M., Srinivas, A., Surayanarayan, S.V., Kumar, G.S. and Bhimasankaram, T. (1998) An Experimental Setup for Dynamic Measurement of Magnetoelectric Effect. Bulletin of Materials Science, 21, 251-255.

https://doi.org/10.1007/BF02744978

[31] Grossinger, R., Duong, G.V. and Turtelli, R.S. (2008) The Physics of Magnetoelectric Composites. Journal of Magnetism and Magnetic Materials, 320, 1972-1977. https://doi.org/10.1016/j.jmmm.2008.02.031

Submit or recommend next manuscript to SCIRP and we will provide best service for you:

Accepting pre-submission inquiries through Email, Facebook, LinkedIn, Twitter, etc. A wide selection of journals (inclusive of 9 subjects, more than 200 journals) Providing 24-hour high-quality service User-friendly online submission system Fair and swift peer-review system Efficient typesetting and proofreading procedure Display of the result of downloads and visits, as well as the number of cited articles Maximum dissemination of your research work

Submit your manuscript at: http://papersubmission.scirp.org/ Or contact msa@scirp.org 